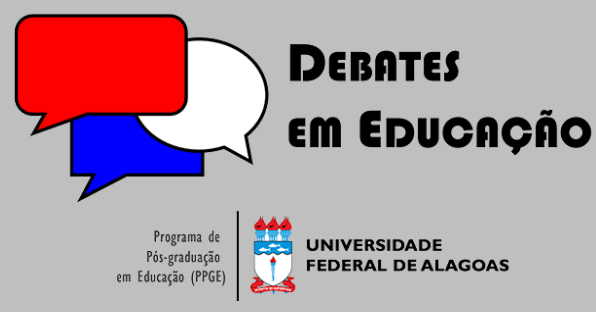

ISSN Eletrônico 2175-6600

Vol. 13 | N. 31 | Jan./Abr. | 2021

Sandro Teixeira Pinto 9 ID

Universidade Norte do Paraná (UNOPAR) sandropinto21@gmail.com

Eliza Adriana Sheuer Nantes

$\theta$ ID

Universidade Norte do Paraná (UNOPAR) elizanantes@gmail.com

\section{GAMIFICAÇÃO NA DISCIPLINA DE REDES DE COMPUTADORES: UMA PROPOSTA DE ELABORAÇÃO DE UM PLANO DE TRABALHO DOCENTE COM O USO DO SIMULADOR PACKET TRACER}

\section{RESUMO}

O simulador Packet Tracer, desenvolvido pela empresa de equipamentos em redes de computadores Cisco Systems Inc, tem a finalidade de preparar profissionais da área de Informática especificamente em Redes de Computadores. Diante disso, o objetivo deste trabalho é elaborar um Plano de Trabalho Docente que apresente a inserção da gamificação com o simulador Packet Tracer na disciplina de Redes de computadores. Enquanto aporte metodológico recorreu-se a metodologia qualitativa de abordagem descritiva com aplicação de atividades, por meio de um Plano de Trabalho Docente, levado a campo em cinco encontros. Como conclusão foi possível elaborar o Plano de Trabalho Docente para aplicação na disciplina de Redes de Computadores com o simulador Packet Tracer.

Palavras-chave: Ensino. Plano de Trabalho Docente. Packet Tracer. Redes de Computadores. Gamificação.

\section{GAMIFICATION IN THE DISCIPLINE OF COMPUTER NETWORKS: A PROPOSAL FOR ELABORATION A TEACHING WORK PLAN USING THE PACKET TRACER SIMULATOR}

\begin{abstract}
The Packet Tracer simulator, developed by the computer network equipment company Cisco Systems Inc, has the purpose of preparing professionals in the area of Informatics specifically in Computer Networks. Therefore, the objective of this work is to elaborate a Teaching Work Plan that presents the insertion of gamification with the Packet Tracer simulator in the discipline of Computer Networks. As a methodological contribution, we used the qualitative methodology of a descriptive approach with application of activities, through a Teaching Work Plan, carried out in the field in five meetings. As a conclusion, it was possible to elaborate the Teaching Work Plan for application in the discipline of Computer Network with the Packet Tracer simulator.
\end{abstract}

Keywords: Teaching. Teaching Work Plan. Packet Tracer. Computer network. Gamification.

Submetido em: 30/04/2020

Aceito em: 26/09/2020

Publicado em: 26/06/2021

do https://doi.org/10.28998/2175-6600.2021v13n31p256-281 


\section{APRESENTAÇÃO}

Segundo Santos (2009), há três décadas, as redes de computadores eram apenas terminais não inteligentes "burros", tinham esta característica por não possuírem memória e processamento próprio e, desta forma, dependiam de um computador central conhecido como mainframe. Atualmente, quase não se vê equipamentos tecnológicos como Notebooks, Smartphones, Tablets, etc., sem estarem conectado a uma rede de computadores e à internet.

Diante deste contexto, os cursos técnicos e superiores, na área de informática, na sua maioria, incluíram uma disciplina denominada de 'Redes de Computadores', com a finalidade de socializar o funcionamento de toda estrutura que compõe uma rede de computadores (MEC, 2016).

De acordo com Lavieri (2013), a estrutura de uma rede de computadores precisa de equipamentos denominados de 'intermediários' que são os Roteadores, Switches, estes objetivam possibilitar o encaminhamento das informações na rede. A empresa Cisco ${ }^{\circledR}$ System S/A, fabricante de equipamentos intermediários, desenvolveu um simulador denominado de 'Packet Tracer', com a finalidade de possibilitar um treinamento com equipamentos virtuais em sua academia $^{1}$, de forma complementar as atividades práticas, realizadas em sala, na forma síncrona.

Os estudos de Fazenda (2015) nos alertam que os equipamentos reais, bem como quase tudo em informática, com pouco tempo de uso torna-se obsoleto, considerando-se, o tempo máximo, em torno de 5 anos. Outro ponto destacado é o fato de que quanto mais completo de recursos for o equipamento mais elevado será o seu valor ficando, muitas vezes, inviável a aquisição constante para os cursos técnicos e superiores para uso na esfera escolar.

Muitas ferramentas de simulação de rede foram desenvolvidas por diferentes empresas, porém o simulador Packet Tracer (PT), desenvolvido Cisco® System, destacase por ser modelo de simulação baseado em ferramenta de aprendizado presente em academias de todo o mundo, tendo como fator facilitador a gratuidade e o fácil acesso.

Como acompanhamos o desenvolvimento do Simulador Packet Tracer, constamos que, com o passar dos anos, a empresa Cisco® System sempre o aperfeiçoou, investindo

\footnotetext{
${ }^{1}$ A empresa Cisco ${ }^{\circledR}$ desenvolveu uma academia de treinamentos para preparar os profissionais da área de redes de computadores no uso de seus equipamentos. Maiores informações acessar: https://www.netacad.com/
} 
em uma abordagem na modalidade gamificada, ou seja, criando possibilidades para os professores elaborarem atividades com tempo para execução, etapas a serem cumpridas e diferentes níveis de dificuldades, objetivando estimular o aluno na realização das atividades.

Um diferencial observado, com as novas versões, mais especificamente a partir da verão 7.0, foi a possibilidade de utilização em sala de aula sem a necessidade de adquirir equipamentos reais como um complemento, internet de todas as coisas e gamificado.

Mediante o exposto, é nesse contexto que o presente estudo se justifica, pois atuamos com o simulado junto ao ensino, há mais de uma década, por isso o elegemos como objeto de investigação, sendo o objetivo deste trabalho apresentar uma proposta de elaboração de um Plano de Trabalho Docente, doravante (PTD), com o uso do simulador Packet Tracer, na disciplina de Redes de computadores, a fim de relatar a nossa prática docente com o uso deste simulador, na modalidade de ensino remoto.

Justificamos, ainda, tal opção metodológica, tendo em vista que apesar de a informática ter se desenvolvido muito, ao longo dos últimos anos, alterando, sobretudo as práticas sociais no campo do trabalho e das formas de interações humanas, na área educacional, no Brasil, somente a partir de março de 2020, em função da pandemia, provocada pelo vírus Sars-CoV-2, conhecido como Coronavírus ou Covid-19, o ensino voltou-se, com maior ênfase, para a exploração da tecnologia, exigindo do professor o uso e o domínio de ferramentas digitais, em virtude da necessidade do distanciamento social. Assim, é nesse contexto que a presente pesquisa foi aplicada, durante o período de pandemia, na modalidade de ensino remoto, ou seja, as atividades ocorridas na sala de aula foram transpostas para a plataforma digital Microsoft $₫$ Teams, realizadas de forma síncrona, no dia e horário normal da disciplina, conforme apresentaremos na metodologia deste trabalho.

Para tanto, o presente trabalho organiza-se desta forma: a seção 1 apresenta uma revisão de literatura sobre pesquisas similares, com o mesmo objeto investigado; a seção 2 versa sobre gamificação na educação e Redes de computadores; a seção 3 relata mais detalhes sobre simulador Packet Tracer; a seção 4, por sua vez, apresenta a metodologia na qual ancoramos a pesquisa; na sequência, na seção 5 , tem-se os resultados e discussões e, por fim, na seção 6, tem-se as proposições finais. 


\subsection{Pesquisas Similares}

Esta subseção apresenta uma seleção de trabalhos que elegeram o Simulador Packet Tracer como um objeto de ensino em sala de aula. Para tanto, elegemos a base de dados Google Acadêmico, tendo como palavra-chave "Simulador Packet Tracer", cujos resultados nos levaram as pesquisas de Lu e Lin (2012), Sllame e Jafaray (2013) e Voss et. al. (2012).

O trabalho dos autores Lu e Lin (2012) relatam algumas características do Packet Tracer, como ser possível visualizar o processo de envio de pacotes ${ }^{2}$, apresentar informações do encapsulamento dos pacotes, fornecer uma interface gráfica com o usuário e com tempo real de resposta, possibilitando, assim, ao aluno ter uma visão abrangente de redes de computadores e dos efeitos de animação possíveis de serem explorados no processo de aprendizagem, com flexibilidade na montagem de cenários de redes para os instrutores.

No trabalho, o autor apresenta que os objetivos vão desde investigar a relação entre a interatividade e as percepções positivas dos alunos sobre o Packet Tracer; a exploração da relação entre os alunos com percepções positivas do Packet Tracer com sua autoavaliação no resultado de aprendizagem, até a exploração da relação entre a percepção dos alunos do Packet Tracer e a autoavaliação, bem como a intenção de uso no futuro. Essa pesquisa foi realizada em uma universidade do norte de Taiwan, junto a 43 alunos do "Curso Introdutório de Tecnologia da Informação". A análise dos dados foi feita por meio de questionários em quatro partes: levantamento de dados como sexo, idade e tempo de uso do computador; interatividade do Packet Tracer percebida pelos alunos; a percepção do aluno, com relação ao Packet Tracer e a autoavaliação, com relação à aprendizagem após o uso do simulador.

Na síntese dos resultados é apresentado que os alunos sentiram que estavam jogando jogos de computador, durante o processo de aprendizagem, assim por meio dos recursos de visualização do Packet Tracer e, com isso o aluno pode melhorar sua compreensão das redes de computadores com conceitos de forma mais eficaz.

Já o trabalho dos autores Sllame e Jafaray (2013) apresentou o uso da ferramenta de simulação para auxiliar o processo educacional, no curso de engenharia de redes de computadores, isso porque, segundo os autores, está cada vez mais difícil implementar laboratórios reais devido ao alto custo de equipamentos e montagem dos laboratórios.

\footnotetext{
${ }^{2}$ Termo utilizado para envio de informações na rede de computadores.
} 
Sendo assim, o autor relatou que o uso de simuladores aumentou a participação dos alunos no processo de ensino e aprendizagem dos conceitos de redes de computadores.

O objetivo desse trabalho foi analisar a efetividade de simuladores no processo de aprendizagem em Redes de Computadores, como resultado, os autores Sllame e Jafaray (2013) relatam que os alunos apresentaram pensamento crítico, habilidades de comunicação e, dessa forma, conseguiram fornecer soluções de problemas nas redes. Além disso, o corpo docente conseguiu observar e considerar os problemas que os alunos enfrentaram quanto ao uso dos simuladores.

O trabalho dos autores Voss et. al. (2012), não diferente dos anteriores, apresentou uma proposta na utilização de simuladores para o ensino de Redes de Computadores, com novas práticas pedagógicas, a fim de contribuir no processor de ensino e aprendizagem. $O$ objetivo desse trabalho foi apresentar sugestões para o desenvolvimento da disciplina de Redes de Computadores, com utilização de simuladores, conhecidos também por laboratórios virtuais, com base nos planos de ensino de 3 instituições, UFSM (Universidade Federal de Santa Maria), ULBRA (Universidade Luterana do Brasil) e UNIFRA (Universidade Franciscana), na graduação, testando-se diferentes simuladores ${ }^{3}$.

Com isso, o autor pôde concluir que os simuladores estudados atendem os objetivos da disciplina de Redes de Computadores, sendo viável e contribuindo para uma melhor reflexão e compreensão dos assuntos selecionados da disciplina. Ainda, os simuladores Packet Tracer, Jim Sim, Net Simk, OPNET IT Guru e SireViW são indicados para as atividades envolvendo os assuntos de Redes de Computadores com uma interface gráfica. Após termos apresentado estudos similares, na sequência, passemos à revisão de literatura.

\section{REVISÃo BIBLIOGRÁFICA}

Esta seção apresenta os conceitos gerais sobre Gamificação no ensino e Redes de Computadores, a fim de apresentar uma proposta de elaboração de um PTD no curso Técnico em Informática, junto à disciplina de Redes de Computadores.

\footnotetext{
${ }^{3}$ Foram selecionados os seguintes simuladores: Packet Tracer, CNet, GNS3, Jimsim, NCTU Network Simulator, NetSimK, Network Simulator - ns-2, OPNET e SireViW, porém, devido a problemas de restrições com instalação e configuração, alguns foram excluídos dos testes, são eles: Cnet ,ns-2, NCTU Network Simulator e GNS-3.
} 


\subsection{Gamificação na Educação}

O conceito de gamificação na educação, apesar de ser apresentado com diferentes seleções lexicais, parece apresentar como ponto assonante, independentemente do autor, que envolve uma determinada finalidade e, para tal, estabelece ações motivadoras para seu cumprimento, conforme estudos a seguir.

Deterdinget et al. (2011) destacam que na gamificação tem-se "o uso de elementos (em contraste ao uso de jogos propriamente ditos) de design (ao invés de tecnologias baseadas em jogos) de jogos (ao invés de atividades lúdicas ou brincadeiras) em contextos de não jogo".

Já para Zichermann e Cunningham (2011) pontuam que a gamificação explora os níveis de engajamento para resolução de problemas. Tais ações, tendem a motivar o estudante no processo de aprendizagem, inclusive impulsionam seu desenvolvimento cognitivo (SCHMITZ; KLEMKE; SPECHT, 2012). O resultado disso é que a gamificação contribui para o aprendizado de forma eficaz, desenvolvendo a atenção, melhorando a retenção de conteúdos, por parte do aluno (CAMPIGOTTO; McEWEN; DEMMANS, 2013).

As pesquisas de Vianna et al. (2013), ampliam as asserções anteriores e destacam que a gamificação é considerada um mecanismo no formato de jogo abrangente, com a finalidade de resolução de problemas, motivação e engajamento.

Outro enfoque é a gamificação também poder ser um processo de melhoria de serviços e objetos, utilizando tanto os elementos do jogo quanto o comportamento de pessoas (HAMARI; KOJVISTO; SARSA, 2014).

Imbricando-se interação e aprendizagem, pode-se dizer que a gamificação é um modelo moderno de interação que proporciona processos de aprendizagem, envolvendo pessoas, com ações materializadas em forma de jogos, voltados para a construção de objetos com interações, a fim de alcançar um objetivo. (BRAGA e OBREGON, 2015).

Os autores Gomes, Tedesco, Melo (2016, p.49) pontuam que "A gamificação na educação se propõe, então, a utilizar estilos, dinâmicas e pensamento de jogo em contextos educacionais como meio para a resolução de problemas e engajamento dos sujeitos da aprendizagem". Tais proposições são corroboradas por Correia (2018) e Fadel et al. (2014), pois os autores destacam que a gamificação pode ser uma aplicação de recursos de jogos em atividades que não compreende como jogos.

Assim, a partir de todos esses posicionamentos sobre a gamificação, é preciso analisar quando um simulador ou um aplicativo é gamificado. Para isso é necessário 
identificar características com atividades e elementos que envolvam jogos, com níveis ou etapas a serem cumpridas mediante a uma premiação.

Conforme Fadel et al. (2014, p.7), "a gamificação tem intuito de aumentar a motivação, o que contribui para o engajamento do usuário. [...] captura dos jogos a sua essência, ou seja, os elementos e mecanismos que proporcionam ao usuário maior motivação e engajamento".

No ensino, a gamificação apresenta objetos para desenvolver a aprendizagem de forma a despertar o aluno na resolução de problemas, trazendo o que acontece no mundo corporativo para a escola: "[...] assim como as empresas têm usado os games para motivar e fidelizar os clientes, também as escolas poderiam usar esses mesmos recursos para aumentar o interesse dos alunos na aprendizagem" (LEFFA, 2014, p. 1).

A fim de garantir o interesse dos alunos na aprendizagem, a gamificação constitui-se na utilização de cenários próprios da disciplina proposta, objetivando encontrar desafios e problemas e resolvê-los de forma prazerosa e com entretenimento. (NANTES, et al. 2017).

No que tange ao entretenimento, a gamificação se propõe a fazer com que as pessoas consigam, de maneira divertida, executar tarefas de uma forma mais agradável. Segundo Alves (2019, p.37) uma pessoa pode usar três plataformas de entretenimento, como: "[...] um jogo preferido no seu celular/smartphone, um outro jogo mais robusto em seu console e um jogo especial instalado no computador pessoal" (ALVES, 2019 p.37).

Com o avanço dos smartphones, o site pesquisa Games Brasil atesta que eles são a plataforma preferida para os jogadores, segundo pesquisa realizada em 2018 :

Quando perguntamos sobre as plataformas em que costumam jogar, notamos que o smartphone se mostrou como a plataforma mais utilizada, uma informação observada na PGB 2017 que foi reforçada nesse ano. As três plataformas mais utilizadas são o celular/smartphone $(84,3 \%)$, o console $(46,0 \%)$ e o computador (44,6\%). Elas são as mesmas quando comparamos os resultados da versão 2017 da Pesquisa Game Brasil, porém, o smartphone nunca foi tão utilizado quando comparados com as outras plataformas de jogo (BRASIL, 2018, p. 6).

Isso demostra que os smartphones são equipamentos que os professores podem utilizar como ferramenta no processo de aprendizagem, pois permitem a exploração de jogos.

Os jogos, de forma geral, são parte de uma estratégia mais ampla, chamada de pensamento de jogo, que consiste em usar a diversão para resolver problemas que acontecem na vida real (MISHRA, 2010). 
Segundo Marczewski (2014), o pensamento de jogo é um conceito maior, separado em quatro categorias, conforme Figura 1: Jogos/brinquedos; Gamificação; Jogos; Jogos sérios.

Figura 1 - Matriz das abordagens do pensamento de jogo

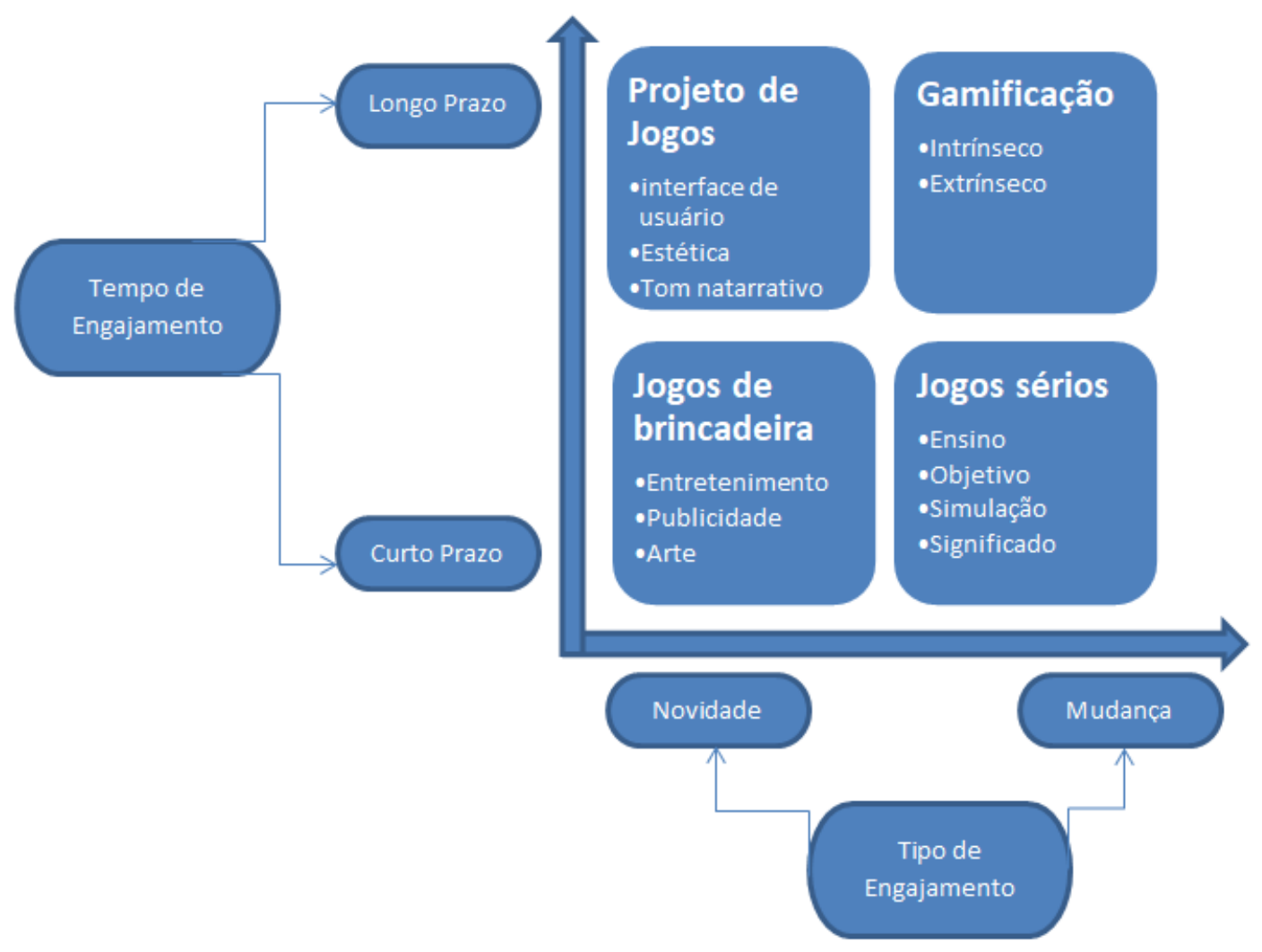

Fonte: Adaptada de Marczewski (2014).

No eixo do tempo de engajamento>curto prazo são os que apresentam compromissos que provocam mudanças comportamentais na maneira de aprender, como jogos educativos, jogos com finalidades e simuladores. No engajamento do tempo>longo prazo não há mudanças comportamentais, é para diversão com apresentações atrativas (MARCZEWSKI, 2014).

A categoria Jogos de Brincadeira trata de jogos que trazem entretenimento ao usuário, com uma interface agradável, normalmente de fácil acesso e com músicas de fundo para provocar uma reação no usuário (MARCZEWSKI, 2014).

A categoria gamificação é, geralmente, definida de acordo com as linhas de pensamento e está classificada em Intrínseca, que é estrutural e de conteúdo; ou gamificação extrínseca, que tem seu uso voltado à motivação ou um design de comportamento, a fim de envolver os usuários. 
A categoria Projeto de Jogos apresenta a estrutura de um jogo, a mobilidade, a interação, a estética e a jogabilidade. Já a categoria Jogos sérios é uma categoria que inclui jogos completos criados com a finalidade de ensino, não sendo apenas diversão, mas um jogo que traz situações reais para um mundo virtual, ou seja, simuladores.

Quanto às perspectivas da qualidade de utilizar os jogos digitais com finalidade educativa, Coutinho e Alves (2016) apresenta uma construção do conhecimento com o maior interesse por parte dos alunos, asseverando que existe uma preocupação quanto à utilização de jogos nas escolas, tendo em vista que não pode ser qualquer jogo, sem nenhuma finalidade específica, sendo necessário desenvolver jogos sérios, com objetivos e finalidades previamente definidos, tanto que os estudos Zichermann e Cunningham (2011) apontam que a gamificação, de forma geral, explora os níveis de engajamento do usuário, a fim de resolver problemas.

Assim, vemos que os Jogos educativos fazem parte da categoria de Jogos Sérios, ou seja, combinam características divertidas com conteúdos pedagógicos utilizados na escola, principalmente em cursos profissionalizantes (MORAS, 2015).

Segundo Hamari, Koivisto e Sarsa (2014), com base em experiências de elementos de jogos, o comportamento dos usuários é evidenciado no processo de melhoria de serviços, de objetos ou de ambientes.

Zichermann e Cunningham (2011) afirmam que as pessoas são motivadas a jogar por quatro razões distintas: (i) obter o domínio de determinado assunto; (ii) aliviar o estresse; (iii) buscar o entretenimento; (iv) promover a socialização. Além disso, os autores apontam quatro diferentes aspectos de interação e de entretenimento durante o ato de jogar: (i) quando o jogador está competindo e busca a vitória; (ii) quando está imerso na exploração de um universo; (iii) quando a forma como o jogador se sente é alterada pelo jogo; (iv) quando o jogador se envolve com outros jogadores.

Diante disso, ao usar a gamificação com o propósito no ensino, a ideia é apropriar-se dos elementos de jogos, mas manter-se no desenvolvimento das atividades propostas, explorando habilidades e competências do aluno.

Dessa forma, é possível asseverar que a gamificação não é apenas jogar por jogar, tento em vista tratar-se de um processo pelo qual o usuário tem uma interação direta com o mundo virtual executando tarefas, resolvendo problemas que são similares ao mundo real, de forma intuitiva e divertida. 


\subsection{Redes de Computadores}

As Redes de Computadores são um conjunto de dispositivos interconectados com a finalidade de potencializar diversas atividades no dia a dia das pessoas, com troca de informações e compartilhamento de recursos (MACEDO et al., 2018)

No que se refere à troca de informações, no passado tínhamos apenas os computadores, como Desktop ou Notebook e impressoras, hoje é possível a troca de informações com mais equipamentos, como telefones VOIP (Voz sobre Internet Protocol), celulares (Smartfone), tablets, ou qualquer dispositivo que tenha capacidade de processamento de dados (PUPPI, 2013).

Com o aumento de equipamentos interligados em redes foi necessário que houvesse uma denominação para qualquer um que estivesse conectado, desta forma todos os equipamentos citados são chamados de Hosts (CANTU, 2003).

Com os Hosts conectados é possível trocar e compartilhar dados em redes, compartilhar recursos de hardware e software, que é um dos principais motivos para o surgimento das redes. Porém para a troca e compartilhamento de informações é preciso que existam alguns elementos como, por exemplo, Transmissor, Receptor e canal de comunicação (MACHADO; MAIA, 2013).

Como os termos estão claros, o equipamento Transmissor tem por finalidade enviar a informação ao Receptor, através de um canal de comunicação conforme ilustra a

Figura 2. Tudo isso acontece de forma dinâmica, ou seja, no mesmo tempo em que um equipamento é transmissor, em outro momento, ele se torna o receptor, isso porque dependendo do tipo de transmissão que poderá ocorrer (MACHADO; MAIA, 2013).

\section{Figura 2 - Transmissor, receptor e canal de comunicação}

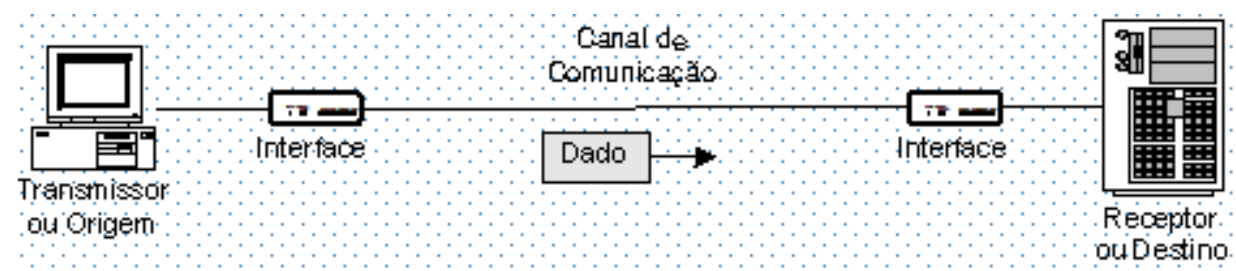

Fonte: Machado e Maia(2013).

Segundo Odom (2008), os Equipamentos de Redes são separados por duas categorias, Intermediários e Finais. Os Equipamentos Intermediários são aqueles onde as informações são encaminhadas através da rede, são exemplos os roteadores, switches, hubs e Access Point. Os equipamentos finais que são praticamente os transmissores e receptores, são aqueles em que a informação é transmitida ou recebida, neste rol 
encontram-se os Desktops, Notebooks, Smartphones, entre outros. Após termos apresentado a revisão bibliográfica, na sequência, passemos ao simulador Packet Tracer.

\section{O SIMULADOR PACKET TRACER (PT)}

O Packet tracer é um simulador de redes de computadores criado pela empresa Cisco ${ }^{\circledR}$ Systems Inc, com a finalidade de preparar profissionais de informática para projetar, configurar e solucionar problemas de redes e o uso dos equipamentos desenvolvidos pela empresa dentro do Networking Academy, Cisco (2020) programa de desenvolvimento de habilidades em redes da própria empresa.

O simulador oferece um ambiente totalmente visual, com animações gratuitas que modelam cenários complexos, sem a necessidade de equipamentos físicos. Trata-se de um simulador para o ensino e a aprendizagem, é fácil de trabalhar e faz com que o usuário ganhe mais confiança no ambiente de trabalho (SHEIKH, 2014). A Figura 3 mostra a tela principal do Packet Tracer.

Figura 3 - Tela Principal Packet Tracer versão 7.2.1.0218

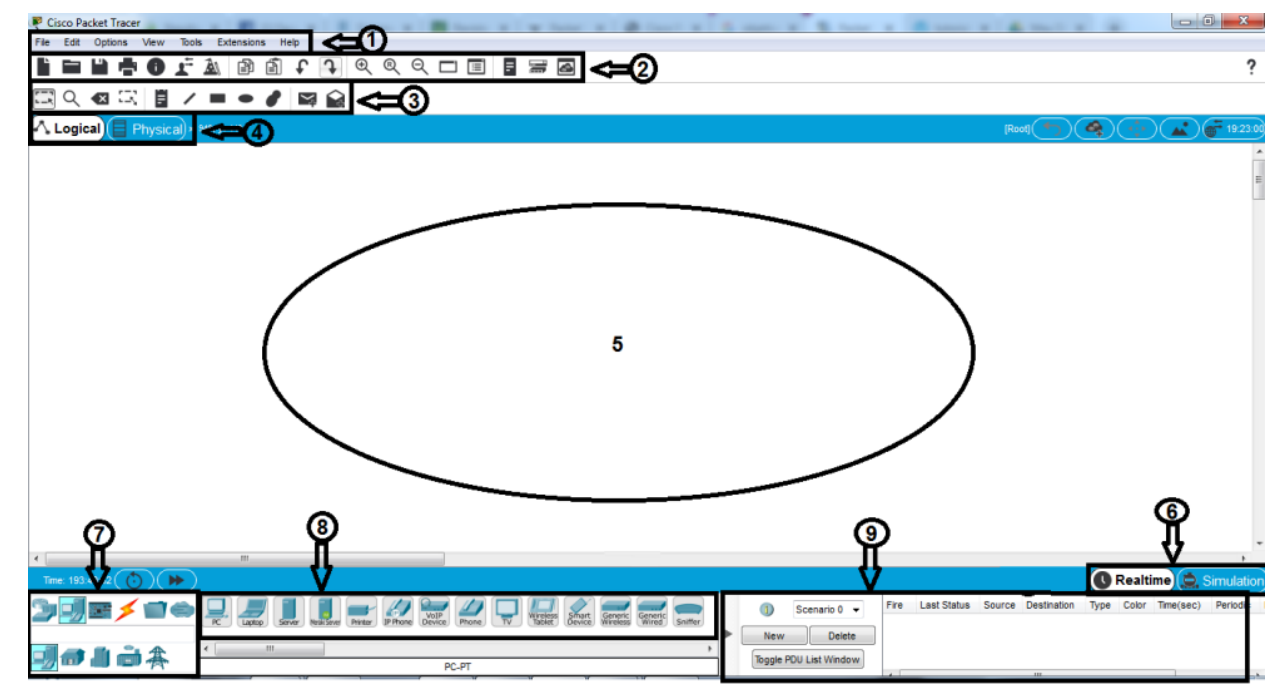

Fonte: Adaptada do Simulador (2020).

A Figura 3 apresenta de forma numérica as barras e botões do simulador. A fim de ficar mais didático é apresentada uma numeração que ora explicitamos, sendo: (1) é a barra do menu, que compõe os itens Arquivo, Editar, Opções, Exibir, Ferramentas, Extensões e Ajuda. Nessa barra é possível encontrar comandos básicos como 'Abrir, Salvar, Salvar como' com a extensão de arquivo própria do Packet Tracer o Pkz, Imprimir, configurações e preferências nesses menus.

É possível, também, acessar o Activity Wizard no menu Extensões, este item fornece uma ferramenta de avaliação que permite criar cenários de rede específicos, para 
serem atribuídos no processo de aprendizagem dos alunos; (2) é a barra de ferramenta principal, que fornece ícones de atalho para os comandos de menu mais utilizados; (3) é a barra de ferramentas comum, que fornece acesso a essas ferramentas de área de trabalho comumente usadas, sendo possíveis ações como: 'Selecionar, Inspecionar, Excluir, Redimensionar forma, Inserir nota, Desenhar, Adicionar simples PDU (Protocol Data Unit) e Adicionar complexo PDU';(4) são botões de seleção para escolha da área de trabalho entre Lógico (Logical) ou Físico (Phisical). No ambiente Logical, permite criar um Novo Cluster, Mover Objeto e Definir Fundo.

O ambiente Physical, apresenta uma barra que permite navegar, simulando locais físicos, como criar uma nova Cidade, um novo Edifício, uma nova sala, e também mover o objeto.

Ainda na Figura 3, o item 5 apresenta a área de trabalho, onde será montado o cenário de uma rede de computadores, a fim de visualizar, analisar e fazer as simulações, testes e identificar possíveis problemas no cenário, nos equipamentos ou até mesmo nas configurações.

O item 6, Figura 3, apresenta dois botões tempo real (realtime) e simulação (simulation) o botão Realtime pressionado permitirá que o usuário faça todas as configurações necessárias para o funcionamento da rede, ou seja, em tempo real.

Já o outro botão Simulation, quando pressionado apresenta o funcionamento do cenário com o movimento ou não de pacotes entre os equipamentos para testes do cenário montado; o item 7 , Figura 3, é a caixa de seleção dos equipamentos de rede que contém os tipos de equipamentos e conexões disponíveis, os itens na parte de baixo poderão ser alterados de acordo com os itens selecionados na parte de cima; no item 8, Figura 3, temos a caixa de seleção que específica o equipamento, aqui poderá escolher o modelo do equipamento selecionado no item 7, Figura 3, é importante ressaltar que os modelos aqui apresentados é exclusivamente do fabricante Ciscoß; o item 9, Figura 3, é a janela de controle de movimentação de pacotes, onde é possível efetuar o teste do cenário montado e identificar se está ou não funcionando.

De acordo com os estudos sobre o aprendizado de Redes de Computadores, entendemos que o simulador Packet Tracer apresenta características como o fato de cada equipamento ser como se fosse uma peça de montagem na qual cada componente de uma rede tem sua função específica que, após a conexão entre eles, permite que uma rede de computadores funcione e, desta forma, possibilite a construção do conhecimento, através do funcionamento de uma rede de computadores interconectados. 
Segundo Litto e Formiga (2012) o objeto de aprendizagem é uma ferramenta virtual que trabalha com o uso de pequenos segmentos de conteúdos metodológicos científicos, sendo utilizados no desenvolvimento do processo de ensino e de aprendizagem para os alunos. A formação do conhecimento complexo se desenvolverá através da combinação dos vários segmentos entre si. Desta forma, o objeto de aprendizagem é análogo a uma peça de montagem, que pode ser combinada com outras peças na formação do conhecimento.

Gasque (2016) ressalta que o objeto de aprendizagem serve como um material de apoio que inclui diversos conteúdos e atividades/tarefas focadas no processo de ensino e de aprendizagem. Desse modo, esse recurso tecnológico como o simulador Packet Tracer, permite a formação e a construção de diversificados campos estratégico que são distribuídos em pequenos componentes educacionais, agrupando-se em um único objetivo, que é propiciar a aprendizagem do aluno. Após termos apresentado o simulador Packet Tracer, na sequência, será apresentado à metodologia da pesquisa.

\section{METODOLOGIA}

Nesta seção será apresentado o desenvolvimento da pesquisa, a metodologia utilizada, seus participantes e lócus da pesquisa, bem como os materiais e instrumentos de coleta de dados que sustentaram a criação do Plano de Trabalho Docente, doravante PTD.

Para levar a campo a presente pesquisa, cujo objetivo é apresentar a elaboração de um PTD com o uso do simulador Packet Tracer com gamificação, na disciplina de Redes de Computadores, por meio da realização de uma série de atividades da academia Cisco, elaboramos um PTD, segundo estudos de Gasparin (2007), pois permite ao professor organizar a realização das atividades.

A metodologia de pesquisa é qualitativa, do tipo descritiva exploratória, pois é utilizada para explorar distinções para mensurar com cientificidade um determinado lócus de pesquisa, permitindo ao pesquisador analisar dados com uma interpretação mais detalhada (BAUER e GASKELLI, 2017).

Segundo Creswell $(2014$, p. 67) a pesquisa qualitativa "é uma atividade situada que localiza o observador no mundo", consistindo em "um conjunto de práticas materiais interpretativas que tornam o mundo viável." 
Assim, para levar o PTD na prática, inicialmente, foi elaborado um PTD, seguindo as proposições de Gasparin (2007), que sugere cinco etapas: (i) Prática Social Inicial; (ii) Problematização; (iii) Instrumentalização; (iv) Catarse); e (v) Prática Social Final.

A seguir, apresentamos o quadro de Gasparin (2007), no qual ancoramos nossas ações docente:

Quadro 1 - Plano de Trabalho Docente proposto por Gasparin (2007).

\begin{tabular}{|c|c|c|c|c|c|}
\hline \multirow{2}{*}{$\begin{array}{c}\text { PRÁTICA } \\
\text { (zona de } \\
\begin{array}{c}\text { desenvolvimento } \\
\text { real) }\end{array} \\
\begin{array}{c}\text { Prática Social Inicial } \\
\text { do Conteúdo }\end{array}\end{array}$} & \multicolumn{4}{|c|}{$\begin{array}{c}\text { TEORIA } \\
\text { (zona de desenvolvimento proximal) }\end{array}$} & \multirow{2}{*}{$\begin{array}{c}\text { PRÁTICA } \\
\text { (zona de } \\
\text { desenvolvimento } \\
\text { potencial) }\end{array}$} \\
\hline & Problematização & Instrumentalização & & Catarse & \\
\hline $\begin{array}{l}\text { 1) Apresentação do } \\
\text { conteúdo. } \\
\text { 2) Vivência } \\
\text { cotidiana do } \\
\text { conteúdo. } \\
\text { a) O que o aluno já } \\
\text { sabe: visão da } \\
\text { totalidade } \\
\text { empírica. } \\
\text { Mobilização. } \\
\text { b) Desafio: o que } \\
\text { gostaria de saber } \\
\text { a mais? }\end{array}$ & $\begin{array}{l}\text { 1) Identificação e } \\
\text { discussão sobre } \\
\text { os principais } \\
\text { problemas } \\
\text { postos pela } \\
\text { prática social e } \\
\text { pelo conteúdo. } \\
\text { 2) Dimensões do } \\
\text { conteúdo a } \\
\text { serem } \\
\text { trabalhadas. }\end{array}$ & $\begin{array}{l}\text { 1) Ações docentes e } \\
\text { discentes para } \\
\text { construção do } \\
\text { conhecimento. } \\
\text { Relação aluno x } \\
\text { objeto do } \\
\text { conhecimento, } \\
\text { através da } \\
\text { mediação docente. } \\
\text { 2) Recursos humanos } \\
\text { e materiais. }\end{array}$ & 2) & $\begin{array}{l}\text { Elaboração } \\
\text { teórica da } \\
\text { síntese, da } \\
\text { nova postura } \\
\text { mental. } \\
\text { Construção } \\
\text { da nova } \\
\text { totalidade } \\
\text { concreta. } \\
\text { Expressão da } \\
\text { síntese. } \\
\text { Avaliação: } \\
\text { deve atender } \\
\text { às dimensões } \\
\text { trabalhadas } \\
\text { e aos } \\
\text { objetivos. }\end{array}$ & $\begin{array}{l}\text { 1) Intenções do } \\
\text { aluno. } \\
\text { Manifestação da } \\
\text { nova postura } \\
\text { prática, da nova } \\
\text { atitude sobre o } \\
\text { conteúdo e da } \\
\text { nova forma de agir. } \\
\text { 2) Ações do aluno. } \\
\text { Nova prática social } \\
\text { do conteúdo ou } \\
\text { das habilidades e } \\
\text { competências. }\end{array}$ \\
\hline
\end{tabular}

Fonte: Gasparin (2007, anexo 1).

A Prática Social Inicial é o ponto inicial que pretende identificar o saber do aluno. Para tanto, procede-se um diagnóstico prévio que servirá de ponto de partida para o professor retomar e/ou avançar no conteúdo programático que será objeto de reflexão. Outra ação pertinente dessa etapa é o professor apresentar o que será estudado e qual o objetivo, atrelando à vivência do aluno no mundo do trabalho.

Já na Problematização inicia-se a fase de intervenção, visto que na Prática Social já foram mapeadas as possíveis lacunas e o nível de aprendizagem no qual o aluno se encontro. Gasparin (2007, p. 37) destaca que, "de acordo com esta proposta teóricometodológica, as grandes questões sociais precedem a seleção de conteúdos escolares". Para tanto, a utilização de questionamentos, situações-problema, estudo de caso são indicadas. 
Nessa etapa que é subdividida em 3 (Problematização - Instrumentalização Catarse), enquanto metodologia de pesquisa, em sala de aula, optamos pela Metodologia Ativa, tendo em vista que, segundo Fonseca e Mattar (2017), as metodologias ativas compreendem a adoção de estratégias de ensino, contudo o papel central é desempenhado pelo aluno, neste caso voltado para como utilizar o simulador Packet Tracer no mundo do trabalho.

A fase da Instrumentalização ou mediação pedagógica é o momento da aprendizagem no qual foram procuradas respostas para as questões na problematização, por isso é importante o professor adotar uma postura mediadora, no sentido de deixar o aluno protagonizar a sua aprendizagem.

Na fase de Catarse, por sua vez, é o momento em que professor e aluno chegam a um novo olhar de compreensão da Prática Social, visto que a partir de conhecimentos prévios outros saberes foram acrescentados.

E, finalmente, na fase Prática Social final, é onde os alunos poderão colocar na prática tudo que aprenderam durante o processo. É pertinente entender esse 'final' como um ponto de parada, após determinado trabalho a ser realizado e não no sentido literal, visto que o conhecimento é espiral, dinâmico e interativo.

Diante destas fases, para a elaboração desta proposta definidos 5 encontros com os alunos, conforme a Figura 4, apresentada na sequência.

Figura 4 - Encontros com o uso do simulador Packet Tracer

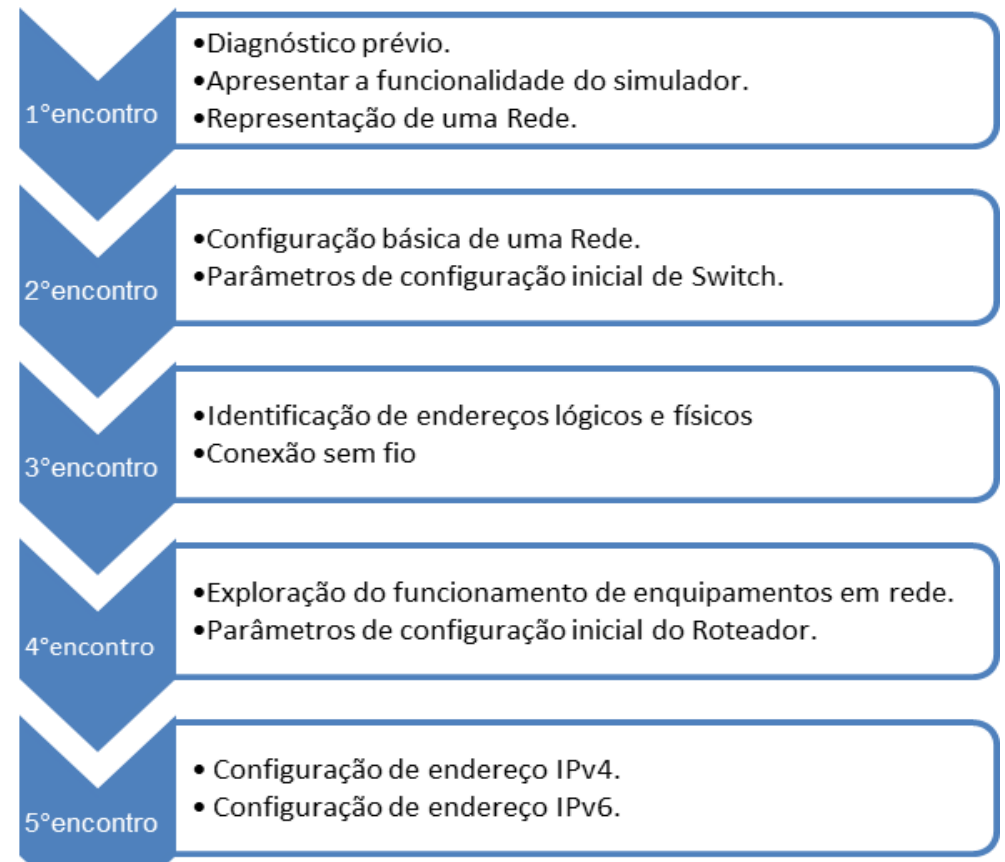

Fonte: Os autores (2020). 
Para a aplicação da pesquisa na escola, primeiramente, foi feita a submissão da proposta, ou seja, a mesma foi submetida ao Comitê de Ética, sendo aprovada, conforme Parecer $n^{0}$. 3.907.596, de 10/03/20204.

Os encontros foram feitos em uma turma de 20 alunos do curso Técnico em Informática para a disciplina de Redes de Computadores, em uma instituição de ensino no norte do Paraná. Em função da pandemia, as aulas foram realizadas na plataforma digital

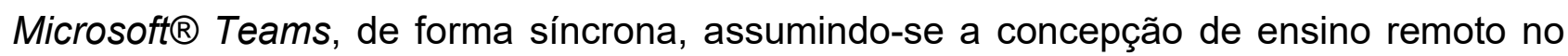
qual a "[...] comunicação é predominantemente bidirecional, do tipo um para muitos, no qual o professor protagoniza vídeo-aula ou realiza uma aula expositiva por meio de sistemas de webconferência." Assim, devido aos espaços geográficos diferenciados, as salas de aula foram "[...] substituídas por uma presença digital numa sala de aula digital", com aulas gravadas disponibilizadas ao aluno a fim de o conteúdo ser "[...] acessado e revisto posteriormente" (MOREIRA; SCHLEMMER, 2020, p. 9). Após contextualização deste percalço de pesquisa, tem-se os resultados e discussões.

\section{$5 \quad$ RESULTADOS E DISCUSSÕES}

Durante o processo de análise dos resultados para elaboração de um PTD, para atender o conteúdo programático da disciplina de Redes de computadores, baseado na primeira etapa de Gasparin (2007), foi preciso, primeiramente, diagnosticar o que os já sabiam sobre redes de computadores.

Para isso foi elaborada a seguinte pergunta: 'Você sabe o que é uma Rede de computadores?' Como resposta menos da metade dos alunos, ou seja, 40\% tiveram contato com redes de computadores, a mesma quantidade teve, parcialmente, deixando $20 \%$ que nunca tiveram contato com redes de computadores. Isso mostra que $60 \%$ dos alunos vão precisar de uma atenção maior por parte do professor para ensinar conforme Gráfico 1.

\footnotetext{
${ }^{4}$ Os resultados que ora socializamos é uma parte do que já foi realizado até o presente momento. Justificamos o fato de o PTD ter sido alterado, no sentido de que a proposta era aula presencial, tendo sido alterado para a modalidade remota, em virtude da pandemia COVID-19 (Coronavírus).
} 
Gráfico 1 Resultado da pesquisa do saber em Redes de Computadores

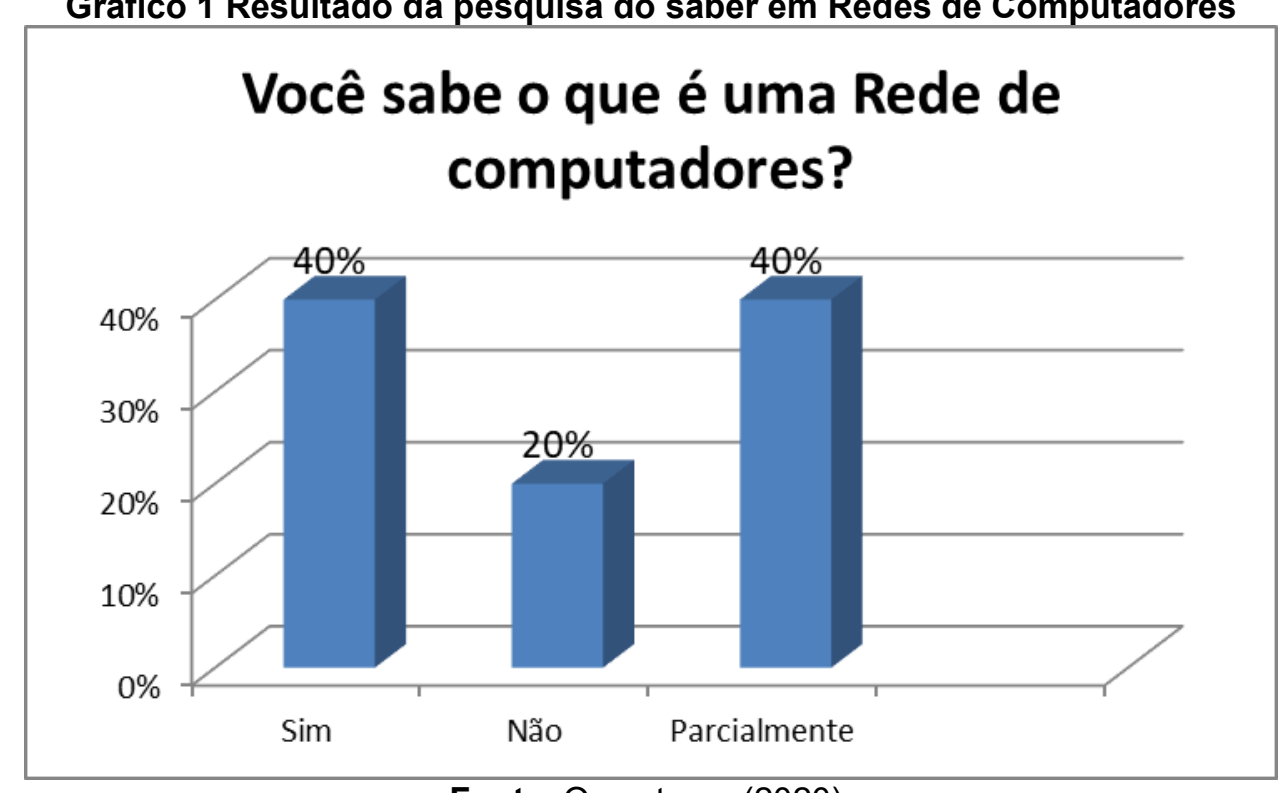

Fonte: Os autores (2020).

Uma segunda pergunta ainda com o propósito inicial de identificar o conhecimento prévio do aluno, pergunta se o aluno 'Você já utilizou algum tipo de simulador?' O Gráfico 2 apresenta que $50 \%$ dos alunos, ou seja, a maior parte nunca teve nenhum contato com simulador, ou pelo menos não conseguiram identificar se isso já aconteceu; $40 \%$ disseram que "sim" e citaram os seguintes simuladores: Virtual Box ${ }^{5}$, Blue Stacks ${ }^{6}$ e o NOX Player ${ }^{7}, 10 \%$ disseram que parcialmente, talvez por ficarem com dúvida se já ou não tiveram contato.

Gráfico 2 - Utilização de simulador por parte do aluno

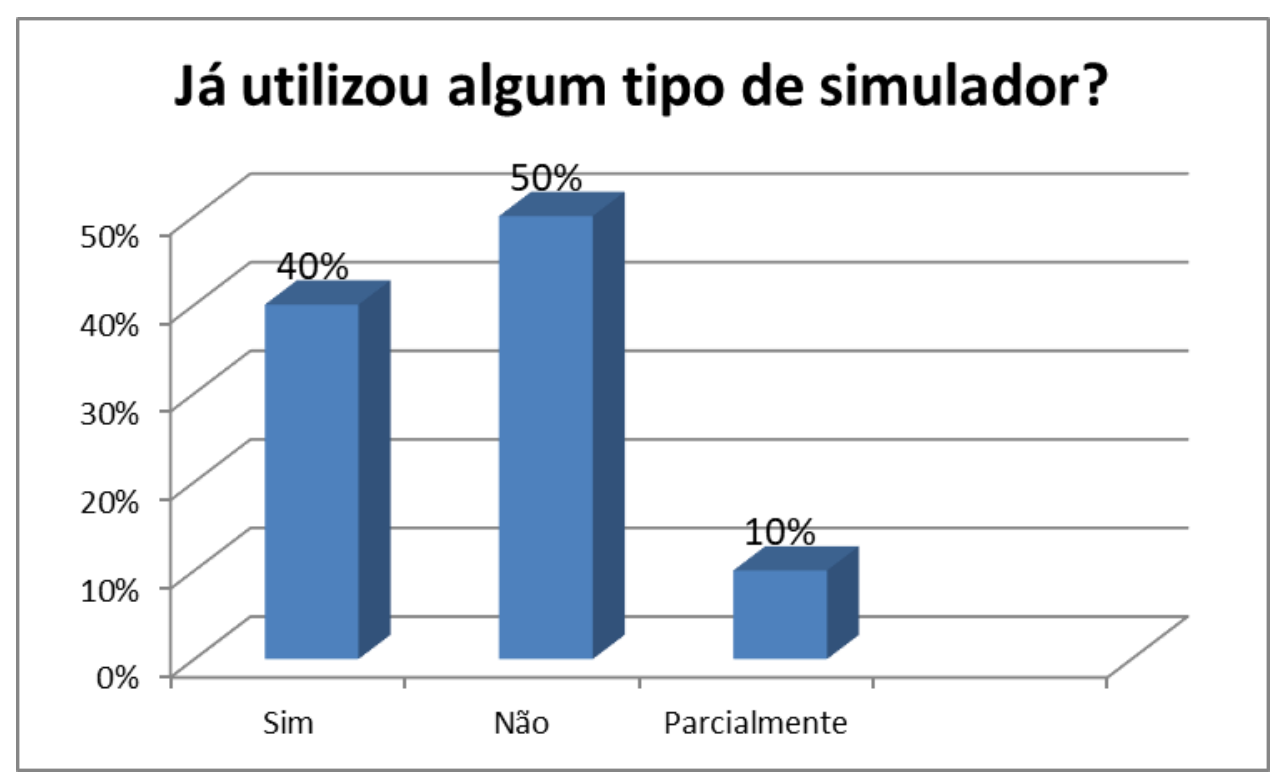

Fonte: Os autores (2020).

\footnotetext{
${ }^{5}$ Virtual Box, simulador de computador virtual

${ }^{6}$ Blue Stacks - simulador de jogos de celulares no computador

${ }^{7}$ NOX Player - simulador de jogos de celulares no computador
} 
A partir destas questões aplicadas em sala de aula, o resultado apresenta que, em média, 50\% nunca utilizou um simulador. Sobre isso, Hung e Bles (2018) dizem que o uso do simulador Packet Tracer observado nas experiências deles, trouxe um resultado adequado para atrelar teoria e prática, sendo considerado uma ferramenta que estimula e motiva a eficiência e transferência da aprendizagem em situações reais.

Já o trabalho de Argomedo (2018) asseverou que o simulador Packet Tracer pode ajudar no processo de ensino e aprendizagem, porém é necessário aplicar práticas com equipamentos reais. O autor assevera, ainda, que o simulador apresentou um desempenho favorável na compreensão e resolução de problemas, desenvolvendo, dessa forma, o raciocínio lógico do aluno.

Tal ação vem ao encontro da proposta de Gasparin (2007), visto que a Pedagogia Histórico Crítica defende que o imbricamento entre teoria e prática motiva e concretiza ações reflexivas, as quais motivam o aluno a buscar possíveis caminhos, o colocando como protagonista da sua aprendizagem, visto que ele mesmo pode fazer uma auto avaliação, (re)tomar decisões e, assim, alcançar uma melhoria continua.

Nesse contexto, a mediação docente é crucial, pois vida "que os alunos não apenas assimilem o saber objetivo enquanto resultado, mas aprendam o processo de sua produção, bem como as tendências de sua transformação" (SAVIANI, 2008, p. 14).

Para maior esclarecimento sobre as ações que permearam a elaboração deste PTD, cabe destacar que após diagnosticar os saberes prévios dos alunos, fez-se o cruzamento de informações com o conteúdo programático da disciplina Rede de Computadores, a fim de saber: (i) diagnosticar o nível de conhecimento prévio do aluno sobre a temática; (ii) contextualizar o Packet Tracer enquanto simulador para o ensino; (iii) atrelar teoria-prática de forma que o aluno possa aplicar os conceitos no mundo do trabalho.

Sendo assim, apesar de o diagnóstico prévio ter apontado que a grande maioria não teve contato com simulador, respaldando-se em estudos que relataram a possibilidade da eficácia do simulador no processo de ensino e de aprendizagem, como as pesquisas apresentadas por Argomedo (2018) e Hung e Bles (2018), elaborou-se um PTD, direcionado para a turma onde um dos pesquisadores deste trabalho atua como docente, considerando-se a realidade escolar, o nível dos alunos, as lacunas diagnosticadas e os objetivos a serem atingidos. Assim, a partir disso, tem-se o PTD detalhado, conforme Quadro 2: 


\section{Quadro 2 - Plano de Trabalho Docente: Simulador Packet Tracer}

\section{PLANO DE TRABALHO DOCENTE: SIMULADOR PACKET TRACER}

Curso: Técnico em Informática

REFLEXÃO

Contextualização do

Packet Tracer

enquanto simulador

para o ensino

\begin{tabular}{c} 
Prática social inicial \\
do conteúdo por meio \\
da reflexão \\
\hline Objetivos: \\
- Reconhecer o uso \\
do simulador como \\
ferramentas para o \\
ensino de Redes de \\
Computadores \\
-Investigar os
\end{tabular}

equipamentos que os

alunos conhecem

e/ou usam.

Conteúdo:

Exploração do

simulador Packet

Tracer para o ensino

de Redes de

computadores.

Vivência do

conteúdo:

(I) O que os alunos já

sabem sobre o uso de

simuladores no ensino?

(II) $\mathrm{O}$ que mais os

alunos sabem sobre redes de computadores?

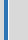

Disciplina: Redes de Computadores

\section{TEORIA}

Construção teórica das práticas que possibilitam o uso do Packet Tracer como simulador para o ensino de Redes de Computadores
Período: $\mathbf{x x}$
PRÁTICA

As aplicações dos

conceitos por meio de práticas

\begin{tabular}{|c|c|c|c|c|c|c|c|}
$\begin{array}{c}\text { Problematização do } \\
\text { conteúdo }\end{array}$ & Instrumentalização & Catarse & $\begin{array}{c}\text { Aplicações práticas do } \\
\text { conteúdo }\end{array}$
\end{tabular}

Discussão sobre o conteúdo:

- Por que estudar gamificação na educação?

- Que dificuldades

há para compreender o funcionamento de simuladores?

Dimensões do

conteúdo a serem trabalhadas:

Conceitual: O que é um simulador?

Quais são os

letramentos digitais necessários para

usar o simulador?

Social: Onde

encontrar o

simulador?

Qual a contribuição

do simulador para o

uso em laboratório?

Histórica: Como e

por que surgiu o

simulador Packet

Tracer?

Escolar: Com que

finalidade o aluno

pode utilizar o

simulador Packet

Tracer?

Estética: Há

diferenças entre o

simulador Packet

Tracer e os demais simuladores

conhecidos pelos alunos?
Ações docentes e discentes: $\quad$ Síntese mental do - Apresentação:

conhecimento dos alunos

sobre o uso do simulador para ensino de Redes de computadores.

- Exposição dialogada do conteúdo, conduzida pelo professor, de forma dialógica.

- Atividades que envolvam os

letramentos necessários para

o uso do simulador. Proceder

à leitura do simulador Packet

Tracer, envolvendo o

letramento digital necessário; investigar o conjunto

de signos presentes em cada fase e as interações necessárias.

Recursos:

Humanos e materiais

(livros; textos diversos; celular,

Datashow e internet).

\section{aluno:}

- Apropriação dos conteúdos

disponíveis em aplicativos de seus ícones e conexões,

juntamente com comandos.

Expressão da síntese:

- Debate sobre o assunto (temas).

- Atividades para o aluno demonstrar sua compreensão sobre o uso do simulador na solução de problemas.

- Atividades de

leitura e análise de outros

equipamentos que possam ser usados no simulador. forma a dominar

\section{Intenções do aluno:}

(I) Conhecer mais sobre o uso do simulador Packet Tracer como ferramenta para a construção do saber. (II) Valorizar o saber crítico reflexivo. (III) Aprender os multiletramentos necessários para o uso do simulador, dentre eles, o digital. (IV) Valorizar o conhecimento adquirido pelos alunos na fase da instrumentalização.

Ações do aluno:

(I) Leitura sobre gamificação na educação; uso de plataformas.

(II) Pesquisar, na mídia impressa e eletrônica, outros aplicativos usados para o ensino de redes de computadores. (III) Socializar entre os alunos o entendimento de novos aprendizados. (IV) Organizar a socialização desse saber.

Fonte: Adaptação do quadro de Gasparin (2007) e do Plano de Trabalho Docente (NANTES, 2014, p. 164). 
Para fins de transposição didática, explicou-se as fases anteriormente descritas no PTD de forma sumarizada: (i) Prática Social Inicial: diagnosticar o quanto o aluno conhece sobre simulador e sobre redes de computadores; (ii) Problematização: apresentar o simulador Packet Tracer, suas funcionalidades gamificadas, os letramentos digitais envolvidos; (iii) Instrumentalização: aplicar atividades gamificadas utilizando o simulador Packet Tracer, aplicar atividades que envolvam múltiplos cenários com problemas, para que o aluno tente resolvê-los; (iv) Catarse: identificar a nova forma de entender a prática social; e (v) Prática Social final: apresentar a apreensão do conteúdo (alunos).

Diante da organização do PTD, foi possível preparar e organizar também o planejamento das aulas por meio de uma sequência didática com cinco encontros e 11 atividades, entre elas 3 gamificadas, conforme mostra Quadro 3.

\section{Quadro 3 - Sequência didática}

\begin{tabular}{|c|c|c|c|}
\hline Ordem & H/aula & $\begin{array}{c}\text { Conteúdo } \\
\text { programático }\end{array}$ & Objetivos \\
\hline $1^{\mathrm{o}}$ & $\begin{array}{l}4 \mathrm{~h} / \mathrm{a} \\
\text { Aula } 1\end{array}$ & $\begin{array}{l}\text { Apresentar a } \\
\text { funcionalidade } \\
\text { do simulador } \\
\text { Representação } \\
\text { de uma Rede }\end{array}$ & $\begin{array}{c}\text { Apresentar o funcionamento do simulador Packet Tracer e todas as } \\
\text { suas funcionalidades. Explicar como as redes afetam as interações, o } \\
\text { aprendizado, o trabalho e a diversão de todos. } \\
\text { Comparar os dispositivos e as topologias de uma LAN com os } \\
\text { dispositivos e as topologias de uma WAN } \\
\text { Descrever os quatro requisitos básicos de uma rede confiável. } \\
\text { Explicar como as tecnologias de rede estão mudando o ambiente } \\
\text { doméstico. } \\
\text { Atividade } 1 \text { - conhecer o simulador }\end{array}$ \\
\hline $2^{\circ}$ & Aula 2 & $\begin{array}{l}\text { Configuração } \\
\text { básica de uma } \\
\text { Rede } \\
\text { Parâmetros de } \\
\text { configuração } \\
\text { inicial de } \\
\text { Switch }\end{array}$ & $\begin{array}{l}\text { Explorar as diferenças na funcionalidade dos equipamentos HUB, } \\
\text { Switch e Access Point. } \\
\text { Configurar os nomes de host em um dispositivo Cisco IOS usando a } \\
\text { CLI( interface por linha de comando). } \\
\text { Descrever os tipos de regras que são necessárias para o êxito da } \\
\text { comunicação } \\
\text { Explicar a necessidade dos protocolos na comunicação. } \\
\text { Explicar como o encapsulamento permite que os dados sejam } \\
\text { transportados pela rede. } \\
\text { Explicar como um switch cria sua tabela de endereços MAC e } \\
\text { encaminha os quadros } \\
\text { Atividade } 2 \text { - montagem de um cenário com HUB } \\
\text { Atividade } 3 \text { - montagem de um cenário com SWITCH } \\
\text { Atividade } 4 \text { - montagem de um cenário com Access point. }\end{array}$ \\
\hline $3^{o}$ & $\begin{array}{l}4 \mathrm{~h} / \mathrm{a} \\
\text { Aula } 3\end{array}$ & $\begin{array}{l}\text { Identificação de } \\
\text { endereços } \\
\text { lógicos e físicos } \\
\text { Conexão sem } \\
\text { fio }\end{array}$ & $\begin{array}{l}\text { Identificar as opções de conectividade do dispositivo. } \\
\text { Identificar as características básicas do cabeamento de cobre. } \\
\text { Descrever o objetivo e a função da camada de Enlace de Dados na } \\
\text { preparação da comunicação para transmissão em determinado meio } \\
\text { físico, seja por cabo ou sem fio. } \\
\text { Explicar como as subcamadas da Ethernet se relacionam com os } \\
\text { campos do quadro. } \\
\text { Analisar o funcionamento dos endereços Físicos IP e Lógicos MAC. } \\
\text { Atividade } 5 \text { gamificada - montagem de um cenário para identificar } \\
\text { os endereços lógico e físico. } \\
\text { Atividade } 6 \text { gamificada - montagem de um cenário para trabalhar } \\
\text { com equipamentos wifi. }\end{array}$ \\
\hline
\end{tabular}




\begin{tabular}{|c|c|c|c|}
\hline $4^{\circ}$ & $\begin{array}{l}4 \mathrm{~h} / \mathrm{a} \\
\text { Aula } 4\end{array}$ & $\begin{array}{l}\text { Exploração do } \\
\text { funcionamento } \\
\text { de } \\
\text { equipamentos } \\
\text { em rede } \\
\text { Parâmetros de } \\
\text { configuração } \\
\text { inicial do } \\
\text { Roteador }\end{array}$ & $\begin{array}{l}\text { Descrever a finalidade da camada de rede na comunicação de dados. } \\
\text { Explicar como dispositivos hosts usam tabelas de roteamento para } \\
\text { direcionar pacotes para si, para um destino local ou para um gateway } \\
\text { padrão. } \\
\text { Descrever os componentes e as interfaces comuns de um roteador. } \\
\text { Definir as configurações iniciais de um roteador Cisco IOS. } \\
\text { Atividade } 7 \text { - Configuração de Roteadores por linha de comando } \\
\text { para ativar o protocolo de endereçamento dinâmico DHCP. } \\
\text { Atividade } 8 \text { - Configuração de Roteadores por linha de comando do } \\
\text { protocolo de roteamento RIP. } \\
\text { Atividade } 9 \text { gamificada - Configuração de Roteadores por linha de } \\
\text { comando do protocolo de roteamento OSPF. }\end{array}$ \\
\hline $5^{\circ}$ & $\begin{array}{l}4 \mathrm{~h} / \mathrm{a} \\
\text { Aula } 5\end{array}$ & $\begin{array}{l}\text { Configuração de } \\
\text { endereço IPv4 } \\
\text { Configuração de } \\
\text { endereço IPv6 }\end{array}$ & $\begin{array}{c}\text { Converter sistemas numéricos decimais e binários. } \\
\text { Descrever a estrutura de um endereço IPv4, incluindo a parte de } \\
\text { rede, a parte de host e a máscara de sub-rede. } \\
\text { Explicar a necessidade do endereçamento IPv6. } \\
\text { da rede. } \\
\text { Explicar como o protocolo ICMP é usado para testar a conectividade } \\
\text { Atividade } 10 \text { - Configuração de endereçamento IPv4. } \\
\text { Atividade } 11 \text { - Configuração de endereçamento IPv6. }\end{array}$ \\
\hline
\end{tabular}

Fonte: Os autores (2020).

Por fim, cabe ressaltar que o PTD elaborado foi devidamente adaptado pelo professor, de acordo com a finalidade, o contexto e o público-alvo da escola onde ele atua. Assim, tendo apresentado os resultados e as discussões, na sequência, tem-se as considerações finais deste trabalho.

\section{CONCLUSÃO}

Iniciou-se o presente trabalho com o objetivo de elaborar um Plano de Trabalho Docente que apresente a inserção da gamificação com o simulador Packet Tracer, na disciplina de Redes de computadores e, para isso, percorreu-se um caminho, a fim de definir o PTD.

Assim, após análise da práxis docente, de forma sumarizada, observou-se, por meio dos estudos teóricos realizados, que o simulador: (i) estimula os alunos a realizarem atividades, paulatinamente, mais complexas, visto que estes concretizam a teoria em atividades práticas; (ii) auxilia o educando a desenvolver habilidades como tomada de decisões e resolução de problemas; (iii) tende a motivar a aprendizagem, por ser de fácil assimilação do conteúdo aprendido e, com isso, complementa o construto teórico materializando-o em atividades que são o simulacro da realidade.

Mediante o exposto, entende-se que este estudo atingiu seus objetivos ao se propor a elaborar um PTD que apresentasse a possibilidades da inserção da gamificação com o simulador Packet Tracer, no âmbito do curso Técnico em Informática, consolidando 
as possibilidades do uso simulador, a fim de propor desafios aos alunos para realização de atividades gamificadas, atrelando, desta forma, teoria e prática.

Procedendo o cruzamento com os dados apresentados nesta pesquisa com os estudos realizados por Lu e Lin (2012), Sllame e Jafaray (2013) e Voss et. al. (2012), notou-se que a compreensão e a reflexão dos conceitos em redes de computadores se tornaram eficazes, utilizando o simulador Packet Tracer, mesmo diante do momento em que vive-se um contexto social atípico, como a pandemia, onde, ficou impossível a utilização dos laboratórios reais para as aulas práticas, ação esta que fez falta.

Diante disso, enquanto docentes responsáveis pela disciplina de Redes de Computadores almeja-se que o simulador apresente uma melhoria na aprendizagem dos alunos, visto que preenche a tríade: teoria-simulador-prática, podendo ser complementado, para ficar ainda mais adequado, com atividades reais, de forma que promova uma interseção entre simulação e prática, preparando, assim, o aluno para a atuação no mundo do trabalho.

Por fim, conclama-se demais pesquisadores e professores da área de informática a investigarem o uso deste ou outros simuladores, como ferramentas para o ensino, de forma que seja possível aumentar a temática ora discorrida para trabalhos futuros, bem como promover maior socialização entre as práticas docentes na esfera acadêmica.

\section{REFERÊNCIAS}

ALVES, T. A. Gamificação em Ambientes Virtuais de Aprendizagem: Uma apresentação e Discussão. 2019. 104 f. Dissertação (Mestrado em Metodologias para o Ensino de Linguagens e Suas Tecnologias) - Universidade Norte do Paraná, Londrina, 2019.

ARGOMEDO, L. J. T. Uso de simuladores y su incidencia en las habilidades para resolver problemas de redes de datos de los estudiantes de una Institución de Educación Superior de Lima. Universidade César Vallejo, 2018.

BAUER, M. W.; GASKELLI, G. Pesquisa qualitativa com texto, imagem e som: Um manual prático. Petrópolis, Rio de Janeiro. Editora Vozes, 2017.

BRAGA, M. C. G.; OBREGON, R. F. A. Gamificação: Estratégia para processos de aprendizagem. Congresso Nacional de Ambientes Hipermídia para Aprendizagem (CONAHPA). 2015. Disponível em: http://conahpa.sites.ufsc.br/wpcontent/uploads/2015/06/ID233 Braga-Obregon.pdf. Acesso em 28 abr. 2020.

BRASIL. Pesquisa Games. Insigths na cultura Gamer, 2018. Disponível em: https://rdstation- 
static.s3.amazonaws.com/cms\%2Ffiles\%2F48816\%2F1525805230Insights PGB18.pdf?ut $\mathrm{m}$ campaign=insights pesquisa game brasil\&utm medium=email\&utm source=RD+Stat ion. Acesso em 28 abr. 2020.

CAMPIGOTTO, R.; McEWEN, R.; DEMMANS, C. Especially social: Exploring the use of an iOS application in special needs classrooms. Journal Computers \& Education, Virginia, v. 60, p. 74-86, 2013.

CANTU, E. T. Redes de Computadores e a Internet. Apostila do IFSC, Campus São José, 2003.

CISCO, N. A. Cisco Packet Tracer. Disponível em: https://www.netacad.com/courses/packet-tracer. Acesso em 28 abr. 2020.

CORREIA, M. E. DA S. Possibilidades Pedagógicas no ensino de Lingua Inglesa com uso de Aplicativos para Smartphone. 2018. 175 f. Dissertação (Mestrado em Letras: Linguagem e Identidade) - Universidade Federal do Acre - UFAC, Acre, Rio Branco, 2018.

COUTINHO, I. J, ALVES R. G. Avaliação de jogos digitais educativos: considerações e conclusões de um levantamento bibliográfico. PPGEduc/UNEB, SENAI/CIMATEC. V. $14 \mathrm{~N}^{\circ} 2$, dez, 2016.

CRESWELL, J. W. Investigação qualitativa e projeto de pesquisa: escolhendo entre cinco abordagens. trad. Sandra Mallmann da Rosa; revisão : Dirceu da Silva. $3^{\mathrm{a}}$ edição. Porto Alegre: Penso, 2014

DETERDING, S., et al. From game design elements to gamefulness: defining gamification. In: Proceedings of the 15th international academic MindTrek conference: Envisioning future media environments. ACM, p. 9-15, 2011.

FADEL, L. M. et al. (Org). Gamificação na Educação. São Paulo: Pimenta Cultural. 2014. 300 p. Disponível em: https://www.pimentacultural.com/gamificacao-na-educacao. Acesso em 28 abr. 2020.

FAZENDA. Decreto $n^{\circ} 194$, de 15 de Julho de 2015. Dispõe sobre anual e regularização de bens móveis, Mato Grosso, Disponível em:

http://app1.sefaz.mt.gov.br/Sistema/legislacao/legislacaotribut.nsf/07fa81bed2760c6b8425 6710004d3940/2e486650b7cdf90484257e84004489c5?OpenDocument. Acesso em 29 abr. 2020.

FONSECA, S. M.; MATTAR, J. Metodologias ativas aplicadas à educação a distância: revisão de literatura. Revista EDaPECI, v. 17, n. 2, p. 185-197, 2017. Disponível em: https://seer.ufs.br/index.php/edapeci/article/view/6509 Acesso em 30 abr. 2020.

GASPARIN, J. L. Uma didática para a pedagogia histórico-crítica. Campinas: Autores Associados, 2007.

GASQUE, K. C. G. D. Objetos de Aprendizagem para o Letramento Informacional. Revista Ibero-Americana de Ciência da Informação, v. 9, n. 2, p. 387-405, 2016 
GOMES, T. C. S; TEDESCO P, C. de A. R.; MELO, J. C. B. Jogos no Design de Experiências de Aprendizagem de Programação Engajadoras. V Congresso Brasileiro de Informática na Educação (CBIE 2016). Sociedade Brasileira de Computação, p. 39-77 cap 2, 2016.

HAMARI, J.; KOJVISTO, J.; SARSA, H. Does Gamification Work? - A Literature Review of Empirical Studies on Gamification. In proceedings of the 47th Hawaii International Conference on System Sciences, Hawaii, USA, Janeiro p. 6-9, 2014.

HUNG, E. L.; BLES, A. M. Potencialidades Didácticas Del Simulador Packet Tracer para La Enseñanza - Aprendizaje de redes de Computadoras. Tecnologia Educativa, 2018.

LAVIERI, D. As Vantagens do uso de Switches de Camada e em Redes Locais: Como otimizar o tráfego de dados em uma rede corporativa com o uso de switches de camada 3. 2013.60 f. TCC (Graduação em Redes de Computadores)- Escola Superior Aberta do Brasil - Especialista em Redes de Computadores, Vila Velha-ES,2013.

LEFFA, V. J. Gamificação adaptativa para o ensino de línguas. In: Congresso IberoAmericano de Ciência, Tecnologia, Inovação e Educação. Buenos Aires. Anais... 2014. p. 1-12. Disponível em: http://www.leffa.pro.br/textos/trabalhos/Gamificacao Adaptativa Leffa.pdf. Acesso em 28. Abr. 2020.

LITTO, F. M.; FORMIGA, M. Educação à distância o estado da arte. São Paulo: Pearson, 2012.

LU, H.; LIN, P. Effects of Interactivity on Students' Intention to Use Simulation-Based Learning Tool in Computer Networking Education. 14th International Conference on Advanced Communication Technology (ICACT), IEEE , Fev, 2012.

MACEDO, R. T. et al. Redes de Computadores. 1. ed. - Santa Maria, RS : UFSM, NTE, 2018.

MACHADO, F. B. /. MAIA. L. P. Arquitetura de Sistemas Operacionais. 5. ed. São Paulo: LTC, 2013.

MARCZEWSKI A. How to use Game Thinking. Gamified UK, Thoughts on Gamification and More, 2014, Disponível em https://www.gamified.uk/2014/10/08/game-thinkinggetting-tools/, Acesso em 30 abr. 2020.

MEC. RESOLUÇÃO Nº 5, DE 16 DE NOVEMBRO DE 2016. Diretrizes Curriculares Nacionais para os cursos de graduação na área da Computação, Brasília,DF, nov 2016. Disponivel em:

http://portal.mec.gov.br/index.php?option=com docman\&view=download\&alias=52101rces005-16-pdf\&category slug=novembro-2016-pdf\&ltemid=30192. Acesso em 29 abr 2020.

MISHRA, G. K. Why Game Thinking is a Bigger Idea Than Game Mechanics. 2010 Disponível em https://humancapitalleague.com/why-game-thinking-is-a-bigger-idea-thangame-mechanics/, Human Capital League. Acesso em 29 abr. 2020. 
MORAS, J. M. Serious games: diseño de videojuegos con una agenda educativa y social. Editorial UOC, 2015.

MOREIRA, J. A.; SCHLEMMER, E.. Por um novo conceito e paradigma de educação digital onlife. Revista UFG, Goiânia, v. 20, 63438, 2020. Disponível em: https://tinyurl.com/y3ezu76q. Acesso em 17 set. 2020.

NANTES, E. A. S. et al. Ensino e Tecnologia : Uma Proposta de Exploração do Duolingo, via plano de trabalho docente, para o ensino de Linguas. Universidade Feevale p. 76-101, 2017.

NANTES, E. A. S. Causo escrito: uma proposta de trabalho sobre leitura, produção textual e análise linguística, via Plano de Trabalho Docente. 2014. 267 f. Tese (Doutorado em Estudos da Linguagem) - Universidade Estadual de Londrina, Londrina, 2014.

ODOM, W. CCENT/CCNA INCD 1 Guia Oficial de Certificação do Exame. 2. ed. Rio de Janeiro: Alta Books, 2008.

PUPPI, M; SCHLEMMER, A. O que mudou na navegação? um estudo comparativo entre computadores fixos e dispositivos de interação móvel. Universidade Federal do Paraná, Departamento de Design, Arcos Disign, Rio de Janeiro, V.7 N.1 Jul, 2013.

SANTOS, S.A.G. Uma nova Proposta de Gestão da Informação para o Serviço Público. 2009. 54 f. TCC (Pós-Graduação em Administração Pública) Fundação Getulio Vargas, Belo Horizonte-MG, 2009.

SAVIANI, Dermeval. Pedagogia histórico-crítica: primeiras aproximações. 10 ed. rev. Campinas, SP: Autores Associados, 2008.

SCHMITZ, B.; KLEMKE, R.; SPECHT, M.. Effects of mobile gaming patterns on learning outcomes: a literature review. Journal Technology Enhanced Learning, 2012.

SHEIKH, R. J. Role of Packet Tracer in learning Computer Networks. International Journal of Advanced Research in Computer and Communication Engineering, v. 3, n. 5, p. 6508-6511, 2014.

SIMULADOR, P. T. Network Academy Cisco. Disponível em: https://www.netacad.com/pt-br/courses/packet-tracer/introduction-packet-tracer Acesso em 19 set. 2020.

SLLAME, A. M.; JAFARAY, M. Using Simulation and Modeling Tools in Teaching Computer Network Courses. International Conference on IT Convergence and Security (ICITCS), IEEE , Dez, 2013.

VIANNA, et al. Gamification, Inc.: como reinventar empresas a partir de jogos. MJV Press: Rio de Janeiro, 2013.

VOSS, G. B. et al. Proposta de Utilização de Laboratórios Virtuais para o ensino de Redes de computadores: Articulando Ferramentas, conteúdos e Possibilidades. (Fase I). Revista Renole - Novas Tecnologias na Educação, v.10, n. 2 Dec, 2012. 
Gamificação na disciplina de arquitetura de redes de computadores: uma proposta de elaboração de um plano de trabalho docente com o uso do simulador Packet Tracer

Sandro Teixeira Pinto | Eliza Adriana Sheuer Nantes

ZICHERMANN, G. ;CUNNINGHAM, C. Gamification by Design: Implementing Game Mechanics in Web and Mobile Apps. Sebastopol, CA: O'Reilly Media, Inc. 2011. 